\title{
3 Research Square

\section{Mapping Revealed Two Additive QTLs and Fourteen Epistatic QTLs for Late Leaf Spot Resistance in a Cultivated Groundnut Breeding Line VG 9514.}

Suvendu Mondal ( $\square$ suvenduhere@yahoo.co.in )

Bhabha Atomic Research Centre https://orcid.org/0000-0001-7638-140X

Babu N. Motagi

University of Agricultural Sciences Dharwad

Anand M. Badigannavar

Bhabha Atomic Research Centre

\section{Research Article}

Keywords: Arachis hypogaea L., Additive QTLs, Epistatic QTLs, Genetic Mapping, LLS resistance, SSR markers

Posted Date: March 10th, 2021

DOI: https://doi.org/10.21203/rs.3.rs-251213/v1

License: (9) This work is licensed under a Creative Commons Attribution 4.0 International License. Read Full License

Version of Record: A version of this preprint was published at Euphytica on August 11th, 2021. See the published version at https://doi.org/10.1007/s10681-021-02908-7. 


\section{Abstract}

A late leaf spot resistant breeding line VG 9514 was bred through interspecific hybridization between Arachis hypogaea L. and Arachis cardenasii. Genetic study involving segregation for late leaf spot resistance in $F_{2}$ and recombinant inbred line population of a cross between VG 9514 X TAG 24 revealed duplicate recessive resistance for the disease. Integration of newly developed SSR markers from A02 chromosome with existing linkage map generated a new genetic linkage map with 278 markers and $2679.1 \mathrm{cM}$ map distances. QTL mapping involving this genetic linkage map and phenotypic field score of late leaf spot identified two major consensus additive QTLs in the A02 chromosome of cultivated groundnut. Epistatic interaction between these two major QTLs was also noticed through an epistatic QTL analysis in Ici-Mapping 4.1. In all the fourteen epistatic QTLs, a common component locus was remained within the major additive QTL at $90 \mathrm{cM}$ in chromosome A02. Sequence analysis within the major additive QTL peaks revealed open reading frame of genes that code LRR domain containing proteins which are involved in disease resistance in crop plants.

\section{Introduction}

Groundnut is an important oilseed crop grown on 4.73 million ha land with a production of 7.50 million tonnes in India. The global total production of groundnut is about 48.75 million tonnes with a productivity of 1.65 tonnes/ha (FAOSTAT 2019). But, the productivity in India (1.42 tonnes/ha) is still below the world average and far below the other key producer like China, USA, Argentina, Brazil etc. One of the major limiting factors for lower productivity in India is the unavailability of acceptable foliar disease resistant cultivars. In India, more than $80 \%$ groundnut is cultivated during rainy season (June to October) wherein major foliar diseases rust (Puccinia arachidis Speg.) and late leaf spot (LLS) (Phaesariopsis personata Berk. and Curtis.) attack the crop and reduces yield upto 50\% (Subrahmanyam et al. 1985; Waliyar 1991). The LLS disease perpetuate in field through overlapped crops and its debris through conidia. Conidia germinate on the leaf surface during periods of high humidity, penetrate either through stomata or directly through epidermal cells and produce intercellular haustoria. Symptoms develop within $10-14$ days at temperatures above $21^{\circ} \mathrm{C}$ (Chupp 1954; Shokes and Culbreath 1997). The adhesion of conidia takes place at $3-6 \mathrm{~h}$ after inoculation followed by germination of spores at $12 \mathrm{~h}$ after inoculation at favorable condition (Leal Bertioli et al. 2010). After establishment in host, it develops circular dark brown to black spots on the lower surface of the leaves and also spreads over petioles, stems and pegs. The symptoms resulted into the dropping of leaves, drying of plant that greatly affects photosynthesis, pod yield and oil quality of seed. Among the several control methods, use of resistant cultivars for cultivation sound better as it is cheap, non-recurring and environment or ecosystem friendly.

Although several sources are available (Pande and Rao 2001) for LLS resistance, usage of such materials are limited due to their poor agronomic features like low shelling percentage, long duration, undesirable pod traits (Wayne et al. 1981). The inheritance pattern for these resistance sources varied based on their genetic background. Tiwari et al. (1984) revealed a digenic recessive inheritance for LLS. While other studies stated polygenic nature of this resistance (Nevill 1982; Green and Wynne 1986, 1987; 
Motagi 2001). Besides, additive gene action also plays a major role towards resistance against this disease causing organism (Kornegay et al. 1980; Hamid et al. 1981; Jogloy et al. 1987). Towards the use of these available resistance sources for breeding, it is important to transfer the resistance genes into elite lines or adapted cultivars. Selection of disease resistance genotypes often challenging in the field as it involves complex interaction between host, pathogen and environment. Compromise of any of these factors may lead to error prone selection and failure of breeding objectives. Tightly linked molecular markers or QTLs would help to select the right genotype in the offseason nursery or absence of sick plots.

Incredible development has happened in the area of molecular marker development, transcriptomics and genomics of groundnut in last ten years. Utilization of available marker information along with the genomics platform helped groundnut research community to generate many linked markers and QTLs for foliar disease resistance, especially for rust and LLS resistance. A recombinant inbred line (RIL) population from the cross TAG $24 \times$ GPBD 4 was used for mapping of LLS resistance by SSR markers and identified a major QTL in A03 chromosome (Khedikar et al. 2010; Sujay et al. 2012). Later, Pandey et al. (2017) confirmed the same QTL using QTL-seq approach and localized it in a $2.98 \mathrm{Mb}$ (131.67134.65 Mb) genomic region of chromosome A03. Subsequently, Han et al. (2018) identified two QTLs for LLS resistance in B05 chromosome using single nucleotide polymorphism-based linkage map. Another three QTLs for LLS resistance were identified on B03, A05 and B05 chromosomes by evaluating a RIL population derived from Florida-07 × GP-NC WS16 (Chu et al. 2019). Later, Clevenger et al. (2018) confirmed these three significant QTL regions through QTL seq analysis. Zhang et al. (2020) detected two significant QTLs on chromosome B09 through GWAS analysis by evaluating the US mini-core peanut collection for both early leaf spot and LLS resistance.

A highly LLS resistant breeding line VG 9514 was developed through an interspecific hybridization between A. hypogaea L. x A. cardenasii in India (Varman 1999). Exploitation of this material in cross breeding program has developed foliar disease resistant genotypes (Badigannavar et al. 2005). Present study was undertaken to tag QTLs for LLS resistance in VG 9514 by using a recombinant inbred line (RIL) mapping population (VG 9514 X TAG 24). The identified markers were also validated in several other genotypes. In future, these markers will be used to pyramid the LLS resistance genes along with rust resistance gene in well adapted high yielding groundnut cultivars in India to prevent the crop losses during the main growing season.

\section{Materials And Methods}

\section{Mapping population and plant materials}

The mapping population was developed from a cross between VG 9514 and TAG 24 and it comprised of 164 RILs. VG 9514, a rust resistant breeding line, belongs to ssp. hypogaea var. hypogaea developed at Tamil Nadu Agricultural University, Vriddhachalam, India (Varman 1999). TAG 24, a well adapted high yielding susceptible groundnut variety, belongs to ssp. fastigiata var. vulgaris developed at Bhabha Atomic Research Centre, Mumbai, India (Patil et al. 1995). The mapping population was developed 
through single seed descent method from $F_{2}$ individuals. The $F_{7}$ progenies were used for phenotyping at different locations and /or seasons and $\mathrm{F}_{8}$ progenies were used for DNA extraction for genotyping.

\section{Phenotyping for LLS resistance}

During the 2004 rainy season (June - October), the two parents and the $F_{2}$ population were evaluated for LLS resistance in the experimental field at BARC, Mumbai, Maharashtra using a modified 9-point scale (Subrahmanyam et al. 1995). Further, the two parents and the $F_{7}$ RILs were screened for LLS resistance in the experimental fields at BARC, Mumbai during rainy season 2007 and 2008 and at Dharwad, Karnataka during rainy season 2008. RILs were sown in randomized block design (RBD) with two replications at all the above locations. The plant spacing was $50 \mathrm{~cm}$ between rows and $10 \mathrm{~cm}$ between plants in $4 \mathrm{~m}$ row. A spreader row of TAG 24 (susceptible) was planted after every four rows of test population and around all sides of the experimental area. Inoculum was prepared by suspending the diseased parts of TAG 24 plants from the previous rainy season in water and agitating vigorously for $30 \mathrm{~min}$. The inoculum containing 20,000 conidia/ml water was mixed with Tween $80(0.2 \mathrm{ppm})$ of water and sprayed over the plants using a medium-volume foot sprayer. High humidity was maintained by irrigating the field in the afternoon with furrow irrigation. Inoculum was sprayed over the test plants and spreader rows in the evening at 50,60, 70 and 80 days after sowing in both $F_{2}$ and RIL population. Disease scoring was done few days before harvest by following a modified 1-9 scale (Subramanyam et al. 1995). The modified 9point scale includes disease score of 1 for $0 \%, 2$ for $1-5 \%, 3$ for $6-10 \%, 4$ for $11-20 \%, 5$ for $21-30 \%, 6$ for $31-40 \%, 7$ for $41-60 \%, 8$ for $61-80 \%$ and 9 for $81-100 \%$ disease severity. RILs with a $1-3$ disease score were designated as resistant and a 4-9 score as susceptible according to Pande and Rao (2001). Pearson correlation analysis of the disease scores on RILs among the environments was performed using PAST ver 3.11 (Hammer et al. 2001).

\section{New SSR marker development from A02 chromosomal sequence}

Based on the earlier findings in our laboratory (Mondal and Badigannavar 2008), QTL loci were coarsely mapped in A02 linkage group. Based on this lead information, the genomic sequence from A02 chromosome of $A$. duranensis accession V14167 was retrieved from Peanutbase (http://www.peanutbase.org).Thereafter sequence information from this retrieved A02 genome was used to identify different classes of repeat loci including di (minimum 6 repeats), tri (5 repeats), tetra (5 repeats), penta (4 repeats), hexanucleotide (4 repeats) and compound repeat motifs using Websat software (Martins et al. 2009). After finding the SSRs, forward and reverse primer sequences were generated using the primer 3.0 (Rozen and Skaletsky 2000) interface in Websat. The following set of parameters were used in designing SSR primer pairs: product length $100-300 \mathrm{bp}$; melting temperature $\left(T_{m}\right) 50-60^{\circ} \mathrm{C}$; primer length $20-25$ nucleotides and GC content $40-50 \%$. The SSR markers were named as LLS SSR (LS 1 to LS 93) (Suppl. Table 1).

\section{Genotyping of RILs}


Genomic DNA of each RIL and parents was isolated from fresh leaf tissue at 30 DAS using a modified CTAB method (Mondal et al. 2005). Integrity and quality of isolated DNA were checked through $0.8 \%$ agarose gel electrophoresis with $\lambda$ DNA as a standard. The DNA samples were quantified using UV-Vis spectrophotometer (Jasco, Cambridge, UK) and adjusted to a final concentration of $10 \mathrm{ng} / \mu \mathrm{l}$. All these newly developed LLS SSR markers were screened for polymorphism between two parents, VG 9514 and TAG 24. The polymorphic primer pairs were used for genotyping of all the 164 RILs. Each $10 \mathrm{ml} \mathrm{PCR}$ reaction volume contained $10 \mathrm{mM}$ Tris- $\mathrm{HCl}\left(\mathrm{pH}\right.$ 9.0), $50 \mathrm{mM} \mathrm{KCl}, 2.0 \mathrm{mM} \mathrm{MgCl}_{2}, 0.2 \mathrm{mM}$ of each primer, $0.10 \mathrm{mM}$ each dNTP (Promega, Madison, USA) and 0.5 U of Taq DNA polymerase (Promega, Madison, USA). SSR amplification was performed under the following conditions: initial denaturation at $94^{\circ} \mathrm{C}$ for 5 min with 35 cycles of $94^{\circ} \mathrm{C}$ for $30 \mathrm{~s}, 50 / 52^{\circ} \mathrm{C}$ for $30 \mathrm{~s}, 72^{\circ} \mathrm{C}$ for 1 min with a final extension at $72^{\circ} \mathrm{C}$ for 10 min. Gel electrophoresis and its documentation was carried out as per Mondal and Badigannavar (2019).

\section{Linkage map construction}

The SSR band scorings were recorded in binary fashion. The genotyping data of all the newly developed polymorphic SSR markers were used for $\chi^{2}$ analysis to test the null hypothesis of 1:1 segregation. The linkage analysis of polymorphic marker was performed using QTL IciMapping ver 4.1 (Wang et al. 2016). Minimum LOD scores of 4.0 were set as threshold for linkage group determination. For ordering and rippling of grouped markers 'nnTwoOpt' and 'SAD' (sum of adjacent distances) command were used, respectively. Both of these commands gave the shortest map distance in the targeted linkage group. The map distance was expressed in centiMorgan (cM) using the Kosambi (1944) map function. Graphical representation of linkage groups was obtained by using the Mapchart version 2.1 (Voorrips 2002). The newly developed SSR markers were also included to the existed genetic linkage map of Mondal and Badigannavar (2019) by following the above mapping protocol in QTL IciMapping ver 4.1.

\section{QTL analysis}

The LLS score 1-3 disease score were designated as resistant and a 4-9 score as susceptible according to Pande and Rao (2001). A $\chi^{2}$ test was performed to test the null hypothesis of 15:1 (susceptible vs. resistant) for LLS resistance in the $F_{2}, 3: 1$ (susceptible vs. resistant) for LLS resistance in RILs. In composite interval mapping (CIM) analysis (Zeng 1994), phenotypic data of the RILs in environments were entered along with the genotypic data of the RILs using WinQTL Cartographer, version 2.5 (Wang et al. 2012). The CIM approach was performed using Model 6, scanning intervals of $1.0 \mathrm{cM}$ between markers and putative QTL with a window size of $10.0 \mathrm{cM}$. A LOD threshold of 3.0 was chosen to declare a putative QTL as significant. Permutations for 500 times were also done while determining the QTL using WinQTL Cartographer using the option "permutations times" with 0.05 significance level. Estimates of the additive effect of each detected QTL, the total LOD score, the total proportion of phenotypic variation explained (PVE) by all the detected QTLs were obtained by fitting a multiple linear regression model that simultaneously included all the detected QTLs for the traits in question. 
Phenotypic data (LLS field score and percent defoliation) of the RILs in each season were entered along with the genotypic data of the RILs in Inclusive Composite Interval Mapping (ICIM) analysis (Li et al. 2007). In order to identify the main QTLs, analyses were performed with QTL IciMapping version 4.1 (Wang et al. 2016) using inclusive composite interval mapping of additive (ICIM-ADD). Additive QTLs were then detected using $1.0 \mathrm{cM}$ speed in scanning by following a stepwise regression method. Towards identification of epistatic QTLs, analyses were performed with QTL IciMapping version 4.1 (Wang et al. 2016) using inclusive composite interval mapping of epistatic modules (ICIM-EPI). Epistatic QTLs were detected using $5.0 \mathrm{cM}$ scanning speed. The probability used in stepwise regression for epistatic QTLs was 0.0001 . To claim a significant epistatic QTL, a LOD threshold of 6.25 was set. Graphics for different QTLs were generated through Mapchart version 2.1 (Voorrips 2002).

\section{Identification of probable genes in the identified QTL region}

Probable candidate genes were searched within the identified QTL region using the nearest flanking marker sequence as boundaries in the A. hypogaea genome browser in Peanutbase (https://peanutbase.org/gbrowse_ahy1.0). The genomic region linked with LLS_QTL was browsed for open reading frames/transcripts present in between those flanking markers as annotated in $A$. hypogaea

L. genome browser.

\section{Validation of markers in other groundnut genotypes}

The marker reactions were also checked in other 20 groundnut genotypes which were phenotyped for LLS score (1-9 scale; Subhramanyam et al. 1995) in 2010 and 2011 during rainy season at experimental field facility at Gauribidanur, BARC, Karnataka, India (Suppl. Table 2). All the four markers flanking in the identified QTL region were used for this validation work. All these primer pair's sequence information was provided in supplementary table 2. Based on the resolved band size in capillary electrophoresis the amplified SSR bands were scored across the lanes comparing their respective sizes. Presence of bands was scored as "1" and absence of band as "0". Marker - trait (LLS resistance) association was detected through single marker ANOVA in PROC.REG (SAS 1998).

\section{Results}

\section{Late Leaf Spot resistance in VG 9514 is mediated by two recessive genes}

The LLS resistance level of VG 9514 was evaluated during rainy season 2003 and 2004 along with TAG 24 and other breeding lines at Trombay, Mumbai. It was found to have a field LLS score of 1-2, whereas the susceptible check TAG 24 had 8 - 9 score. The $F_{1}$ plants from the cross VG 9514 X TAG 24 were grown in rainy season 2005 and was found susceptible to LLS. The $F_{2}$ population obtained from the above $F_{1}$ plants was segregated into 14 resistant and 150 susceptible plants (Table 1 ). The segregation ratio of these $F_{2}$ plants was well fitted into 1:15 ratio that indicated a duplicate recessive resistance in VG 9514 against LLS pathogen. The same $F_{2}$ population was advanced to $F_{8}$ through single seed descent 
method and a RIL population was generated for mapping of these LLS resistance genes. Field evaluation of the RIL population in three different environments revealed 1:3 segregation (resistant: susceptible) in all the environments (Table 1).

\section{SSR polymorphism and linkage map construction}

Of the 93 repeat motifs in LS primer series, 56 were with dinucleotide, 28 with trinucleotide, four with tetranucleotide, two with hexanucleotide and three with compound repeat motif. In the dinucleotide repeat motif, AT/TA was more frequent (37.5\%). While, TAA repeat were found more frequent in trinucleotide repeat class (Suppl. Table 1).Screening for polymorphism between two parents, VG 9514 and TAG 24 revealed that 15 (16.13\%) LS primer pairs were polymorphic. All these 15 new LS markers were used for genotyping in 164 RILs for updating the existing genetic linkage map of Mondal and Badigannavar (2019). Genotyping of 164 RILs revealed that all the new LS markers have followed 1:1 ratio ( $P$ value $=$ 0.21 to 0.89). Linkage analysis placed 15 new LS markers in group A02 along with Cer2, RGC2 and others SSR markers (Fig 1). The marker LS38 amplified two segregating loci. Of the 16 segregating loci, 14 LS markers placed in $48.3 \mathrm{cM}$ map length with an average map interval of $3.45 \mathrm{cM}$ (Fig 1). Genetic mapping had yielded 21 linkage groups that covered $2679.1 \mathrm{cM}$ map distance in total. An average map distance between two markers was $9.7 \mathrm{cM}$ in the whole genetic linkage map. Of the 278 mapped markers, 56 (20\%) had segregation distortion. The smallest linkage map had only two markers and with $8.23 \mathrm{cM}$ distance. The longest linkage map had 19 markers that spanned $354.97 \mathrm{cM}$ distance. All the new LS markers were mapped in A02 along with 10 other previously mapped SSR and RGC markers. A total map distance of $105.2 \mathrm{cM}$ was obtained in linkage group A02 with an average map interval of $4.0 \mathrm{cM}$.

\section{Phenotyping of RILs for LLS resistance in three different environments}

Phenotypic evaluation of RILs for LLS resistance based on 1-9 scaled field score revealed discontinuous distribution except the data on percent defoliation (Fig 2). The highest mean LLS score and coefficient of variation were obtained at Trombay 2007 environment. Percent defoliation data at Dharwad 2008 had the least coefficient of variation and less skewed as compared to field LLS score in other environments (Table 2). Correlation study among the field scores of three environments and percent defoliation data revealed significant positive correlations among them (Table 3). The highest correlation (0.94; $\mathrm{P}=$ 0.0001) was obtained between Trombay 2007 and Trombay 2008 field LLS scores. The lowest correlation value $(0.40, P=0.0001)$ obtained between Trombay 2008 and percent defoliation data in Dharwad. The correlation value between percent defoliation and LLS field scores at Dharwad was $0.55(P=0.0001)$ (Table 3).

\section{Identification of main QTLs for LLS resistance in VG 9514}

Based on QTL cartographer analysis, two major QTL loci were detected in linkage group A02. Both the QTL peaks were above $44 \mathrm{cM}$ apart and no complete linkage among them. The first QTL peak mapped at $33.0 \mathrm{cM}$ in linkage group A02 while the second peak mapped in an extended region ( $77.0 \mathrm{cM}$ to $104 \mathrm{cM})$ at the distal part of A02 group. This extended region of A02 later resolved through QTL Ici-Mapping 
analysis which detected a sharp peak at $89.0 \mathrm{cM}$. Hence, these were two major QTL regions in A02 group that conditioned duplicate recessive resistance against late leaf spot disease in cultivated groundnut. The first QTL peak (in between LS 38b and LS 79 marker) at $33.0 \mathrm{cM}$ in A02 chromosome explained 38.0 $45.3 \%$ phenotypic variation due to LLS field score. While, the second peak at $89.0 \mathrm{cM}$ in A02 chromosome explained 45.5 - 78.0\% phenotypic variation due to LLS field score (Fig 1; Table 4). Both these QTL peaks are $56.0 \mathrm{cM}$ away and have no linkage between them. A QTL for defoliation (in Dharwad 2008) was also obtained in the same map interval (between Ah282b and RGC2) of A02 linkage group that explained $10.3 \%$ phenotypic variation due to defoliation at field. The desirable allele for this defoliation was originated from the VG 9514.

Through QTL Ici-Mapping analysis, a consensus major QTL was obtained in linkage group A02 which explained $41.53 \%$ (average) phenotypic variation due to LLS resistance in groundnut. This particular major QTL was mapped within a $4.3 \mathrm{cM}$ interval in between a SSR marker Ah282b and a resistance gene candidate marker RGC2. The same QTL has an additive effect of 1.4 to 2.1 in term of field LLS score (Table 4). The desirable allele for LLS resistance was originated from the VG 9514. Interestingly, a major QTL for defoliation was also obtained in the same map interval (between Ah282b and RGC2) of A02 linkage group that explained $14.14 \%$ phenotypic variation. One each minor QTL for LLS resistance score and 'percent defoliation' was also detected in Ici-Mapping analysis. The minor QTL for LLS field score was positioned in linkage group A06 in between the marker TC11A04b and PM 377 and explained only 4.4\% variation due to field LLS score in Trombay 2008. The other minor QTL for percent defoliation was mapped in B08 linkage group within the flanking marker TE6 and TE52 and explained 8.6\% variation due to leaf defoliation at Dharwad 2008 (Table 4).

\section{Detection of epistatic QTLs for LLS resistance}

The interactive/epistasis QTL analysis detected a total of 14 epi-QTLs for LLS resistance in cultivated groundnut (Table 5). All these 14 epi-QTLs had a common component QTL focus at $90 \mathrm{cM}$ in A02 chromosome that were interacted with various loci in chromosome A01, A02, B02, A03, B03, A04, B04, A05, A06, B06, B07, B08, A09 and A10 of cultivated groundnut (Fig 3). This common epi-QTL component was also situated in the same map interval (in between Ah282b and RGC 2) with a main additive QTL in A02 group. Of these14 epi-QTLs, seven epi-QTLs were common in all the three tested environments with $\geq 6.3$ LOD score, three were specific for Trombay 2008 and four were common to both Trombay 2007 and 2008. Of these 14 epi-QTLs, an interactive QTL (EQ2-A02.A02_LLS) between the two major additive QTL peaks in A02 group (between $30 \mathrm{cM}$ and $90 \mathrm{cM}$ ) was detected at all three tested environments including average (Fig 1; Fig 3; Table 5).

\section{Validation of markers and candidate gene identification}

Marker reaction in the 20 cultivated groundnut genotypes differing in LLS resistance revealed significant $\mathrm{R}^{2}$ for all the four flanking markers in the two main QTLs. Single marker ANOVA revealed that these markers explained $84 \%$ to $89 \%$ phenotypic variation due to field LLS score (Suppl. Table 2 ). The 
consensus QTL region in between Ah282b and RGC2 markers was corresponding to 1,919,726 bp to 1,945,257 bp of A02 chromosome of $A$. hypogaea. This particular small genomic fragment contains two ORFs Arahy.WJPX1L and Arahy.73EBH2 in Peanutbase (https://peanutbase.org/home). Arahy.WJPX1L codes for glucosyl group transferase protein and Arahy.73EBH2 is a disease resistance protein with LRR domain. The other QTL region (between LS38 and LS79) in A02 corresponds to 2,061,314 bp to 2,550,550 bp in A02 chromosome of $A$. hypogaea and had 46 ORFs within it (Suppl. Table 3). Of these 46 ORFs, 14 ORFs code for disease resistance protein that contain LRR and NB-ARC domains. Of these 14 disease resistance protein, Arahy.V6WQ14 had all the functional domains like TIR (Toll-Interleukin Receptor), NB (Nucleotide Binding) and LRR (Leucine Rich Repeat).

\section{Discussion}

Genetic disease resistance in crop plants is conditioned by various R-genes. These genes were studied in last 50 years and broadly categorized under nine different mechanisms (Kourelis and van der Hoorn 2018). Basically, plants have two-tiered innate immunity system: pathogen-associated molecular patterntriggered immunity (PTI) and effector-triggered immunity (ETI). PTI is initiated by plasma membranelocalized plant pattern recognition receptors, which are receptor-kinase proteins or receptor-like proteins and impart quantitative resistance. Whereas, ETI is initiated by cytoplasmic nucleotide binding (NB)leucine rich repeat (LRR)-type resistance proteins that provide qualitative/oligogenic resistance against plant pathogen (Jones and Dangl 2006).

In the present study, the LLS resistance was derived from VG 9514, an introgressed line from a cross between Co 1 (A. hypogaea L.) x A. cardenasii (Varman 1999). Both the $\mathrm{F}_{2}$ and RIL population of VG 9514 X TAG 24 cross were segregated for duplicate recessive gene (oligogenic) inheritance. Confirmation of duplicate gene inheritance was also made through the study of RIL segregation in case of powdery mildew resistance in diploid wheat Triticum boeoticum (Chhuneja et al. 2012). Based on the QTL study, both of these major recessive genes were mapped in a single linkage group A02 in cultivated groundnut genome (Fig 1). Both of these major QTL peaks for LLS resistance were mapped almost $57 \mathrm{cM}$ apart in a single linkage group and segregated independently. The QTL peak in the proximal end of A02 linkage group correspond to about $0.5 \mathrm{Mbp}$ gene rich fragment in $A$. hypogaea Tifrunner genome, where 46 genes reside in it. Of them, 14 genes were found to have protein domains related to disease resistance protein in crop plants (Suppl. Table 3). The other QTL peak (towards distal end of A02 group) corresponds to a small genomic fragment $(25.5 \mathrm{kbp})$ that has only two ORFs in A. hypogaea Tifrunner genome. Of them, one ORF corresponds to NBS-LRR domain containing disease resistance protein. Apparently both these two major QTLs aligned within $0.6 \mathrm{Mbp}$ in Tifrunner genome assembly. But, practically, both the QTLs were about $57 \mathrm{cM}$ apart in the genetic linkage map of A02 chromosome in this study (Fig 1; Table 4). This discrepancy might be arisen due to evolution of VG 9514 from an interspecific cross [A. hypogaea L. (4x) $x$ A. cardenasii $(2 \mathrm{x})$ ] that may involve insertion, duplication, and/or translocation of chromosome fragment during several backcrosses of derived $\mathrm{F}_{1} / \mathrm{BCF}_{1}$ (colchi-haxaploid/pentaploid) with recurrent parent or homeologous exchanges (Udall et al. 2005). Further sequence analysis revealed that a majority 
R-gene candidates in the tetraploid genome (cv. Tifrunner) are recently produced resulting from gene duplication events after tetraploidation (Song et al. 2019).

Localization of NB-LRR containing R gene and/or R gene clusters in these two major QTL regions implicated the role of ETI mechanism in operating an oligogenic (duplicate recessive) resistance against LLS in VG 9514. Among these two major QTL regions, the distal QTL (at $89 \mathrm{cM}$ in A02) showed significant epistatic interactions with 14 other loci across groundnut genome. Such an elucidation suggested that the process of disease resistance mechanism involved multiple gene interaction in plants that require downstream signaling cascade for induction of programmed cell death to restrict pathogen growth at the site of infection (Coll et al. 2011). Further two additive major QTL loci also had epistatic interaction (Epi-QTL: EQ2-A02.A02_LLS) between them (Table 5). Role of digenic interactions between drought QTLs affecting the performance of one QTL over the other drought QTL has been well documented in various QTL mapping and marker-assisted near isogenic lines development in breeding programs in rice (Dixit et al. 2012; Yadav et al. 2019). In the study, we could find co-localization of percentage defoliation QTL (qDefolA02) with the second major QTL for LLS resistance in A02 chromosome (Table 4: Fig 1). LLS resistance in field is also characterized by the less defoliation in the affected plant. In absence of cognate R-genes in susceptible plants, the pathogen effectors may exert intricate effects on host susceptibility factors that steer host functions to meet the demands of pathogen nourishment or accommodation of pathogen infection structures (Saur and Hückelhoven 2021). In contrast, less defoliation in resistant plant may arise due to the limit of pathogen growth in the point of infection by the action of programmed cell death due to signaling events from cognate recognition of Rgene with avirulence gene product in pathogen.

The present study is the beginning of understanding of digenic recessive inheritance of LLS resistance in cultivated groundnut that could find out the position of two major QTLs and role of other 14 epistatic QTLs in LLS resistance. Future work will be directed towards map based cloning of these two major genes and establishment of their biochemical functions.

\section{Declarations}

\section{Acknowledgement}

Authors acknowledge the support and encouragement received from Head, Nuclear Agriculture and Biotechnology Division, Bhabha Atomic Research Centre, Mumbai, India.

\section{Authors Declarations}

Funding: The work was funded by Department of Atomic Energy, Government of India.

Conflicts of interest/Competing interests: Authors do not have any conflicts of interest.

Availability of data and material: All the data were included in the manuscript 
Code availability: The manuscript is not dealing with any novel code. The software used for QTL analysis is available in open platform.

Authors' contributions: SM designed the concept, generated data, analyzed data, prepared the draft and edited the manuscript. BNM did phenotyping for LLS resistance and edited the manuscript. AMB execute field experiments and edited the manuscript.

Ethics approval: Not applicable (the study does not involve any animals and human).

Consent to participate: Not applicable

Consent for publication: Not applicable

\section{References}

Badigannavar AM, Kale DM, Mondal S. Murty GSS (2005) Trombay groundnut recombinants resistant to foliar diseases. Mutation Breed Newslett Rev 1:11-12

Chhuneja P, Kumar K, Stirnweis D, Hurni S, Keller B, Dhaliwal HS, Singh K (2012) Identification and mapping of two powdery mildew resistance genes in Triticum boeoticum L. Theor Appl Genet 124:10511058

Chu Y, Chee P, Culbreath A, Isleib TG, Holbrook CC, OziasAkins P (2019) Major QTLs for resistance to early and late leaf spot diseases are identifed on chromosomes 3 and 5 in peanut (Arachis hypogaea). Front Plant Sci 10:883

Chupp C (1954) A monograph of the fungus genus Cercospora. Science 1: 120

Clevenger J, Chu Y, Chavarro C, Botton S, Culbreath A, Isleib TG, Holbrook CC, Ozias-Akins P (2018) Mapping Late leaf spot resistance in peanut (Arachis hypogaea) using QTL-seq reveals markers for marker-assisted selection. Frontiers Plant Sci 9: 83. DOI=10.3389/fpls.2018.00083

Coll NS, Epple P, Dangl JL. (2011) Programmed cell death in the plant immune system. Cell Death Differ. 18(8):1247-1256

Dixit S, Mallikarjuna Swamy BP, Vikram P et al. (2012) Increased drought tolerance and wider adaptability of qDTY 12.1 conferred by its interaction with qDTY 2.3 and qDTY 3.2. Mol Breeding 30:1767-1779

FAOSTAT (2019) Food and Agricultural Organization of the United Nations. Data available at http://www.fao.org/faostat/en/\#data/QC. Accessed on 4 January 2021

Green CC, Wynne JC (1987) Genetic variability and heritability for resistance to early leaf spot in four crosses of Virginia-type peanut. Crop Science 27:18-21. 
Hamid MA, Isleib TG, Wynne JC and Green CC (1981) Combining ability analysis of Cercospora leaf spot resistance and agronomic traits in Arachis hypogaea L. Oleagineux 36:605-612

Hammer $\varnothing$, Harper DAT, Ryan PD (2001) PAST: Paleontological Statistics Software Package for Education and Data Analysis. Palaeontologia Electronica 4(1):9pp. Available at: http://folk.uio.no/ohammer/past (last accessed on November 25, 2020)

Han S, Yuan M, Clevenger JP, Li C, Hagan A, Zhang X, Chen C, He G (2018) A SNP-based linkage map revealed QTLs for resistance to early and late leaf spot diseases in peanut (Arachis hypogaea L). Front Plant Sci 9:1012. https://doi.org/10.3389/ fpls.2018.01012

Jogloy S, Wynne JC and Beute MK (1987) Inheritance of late leaf spot resistance and agronomic traits in peanut. Peanut Science 14:86-90

Jones JD, Dangl JL (2006) The plant immune system. Nature 444:323-329

Khedikar Y, Gowda MVC, Sarvamangala C, Patgar KV, Upadhyaya HD, Varshney RK (2010) A QTL study on late leaf spot and rust revealed one major QTL for molecular breeding for rust resistance in groundnut (Arachis hypogaea L.). Theor Appl Genet 121:971-984

Kornegay JL, Beute MK, Wynne JC (1980) Inheritance of resistance to Cercospora arachidimla and Cercosporidium personatum in six Virginia-type peanut lines. Peanut Science 7:4-9

Kosambi DD (1944) The estimation of map distances from recombination values. Ann Eugen 12:172-175

Kourelis J, van der Hoorn RAL(2018) Defended to the nines: 25 years of resistance gene cloning identifies nine mechanisms for R protein function. Plant Cell30:285-299

Leal-Bertioli SCM, De Farias MP, Ialo P, Silva T, Guimarães PM, Brasileiro ACM, Bertiloi DJ, De Aravjo ACG (2010) Ultrastructure of the initial interaction of Puccinia arachidis and Cercosporidium personatum with leaves of Arachis hypogaea and Arachis stenosperma. J Phytopathol 158:792-796

Li H, Ye G, Wang J (2007) A modified algorithm for the improvement of composite interval mapping. Genetics 175:361-374

Martins WS, Lucas DCS, de Souza Neves KF, Bertioli DJ (2009) Websat - A Web software for microsatellite marker development. Bioinformation 3(6):282-283

Mondal S, Ghosh S, Badigannavar AM (2005) RAPD polymorphism among groundnut genotypes differing in disease reaction to late leaf spot and rust. Intl Arachis Newslett 25:27-30

Mondal S, Badigannavar AM (2008) Identification of SSR marker for resistance to late leaf spot in cultivated groundnut (Arachis hypogaea L.). Abstract. $5^{\text {th }}$ International Crop Science Congress (ICSC), April 13-18, 2008, Jeju, Republic of Korea. Pp: 266 
Mondal S, Badigannavar AM (2019) Identification of major consensus QTLs for seed size and minor QTLs for pod traits in cultivated groundnut (Arachishypogaea L.). 3 Biotech9:347. https://doi.org/10.1007/s13205-019-1881-7

Motagi BN (2001) Genetic analysis of resistance to late leaf spot and rust vis-à-vis productivity in groundnut (Arachis hypogaea L.). Dissertation, University of Agricultural Sciences, Dharwad, India.

Nevill DJ (1982) Inheritance of resistance to Cercosporidium personatum in groundnuts: A genetic model and its implications for selection. Oleagineux 37:355-366.

Pande S, Rao NJ (2001) Resistance of wild Arachis species to late leaf spot and rust in greenhouse trials. Plant Disease 85:851-855

Pandey MK, Khan AW, Singh VK, Vishwakarma MK, Shasidhar Y, Kumar V, Garg V, Bhat RS, Chitikineni A, Janila P, Guo B, Varshney RK (2017) QTL-seq approach identified genomic regions and diagnostic markers for rust and late leaf spot resistance in groundnut (Arachis hypogaea L.). Plant Biotechnol J15(8):927-941

Patil SH, Kale DM, Deshmukh SN, Fulzele GR, Weginwar BG (1995) Semi-dwarf, early maturing and high yielding new groundnut variety, TAG 24 . J Oilseed Res 12:254-257

Rozen S, Skaletsky H (2000) Primer3 on the WWW for general users and for biologist programmers. Bioinformatics methods and protocols: Methods in Mol Biol 132:365-386

SAS Institute Inc. (1998) SAS/STAT user's guide, Release 6.03 ed. SAS Institute Inc, Cary, NC.

Saur IML, and Hückelhoven R (2021) Recognition and defence of plant-infecting fungal pathogens. Journal of Plant Physiology 256: 153324. https://doi.org/10.1016/j.jplph.2020.153324

Shokes FM, Culbreath AK. (1997) Early and late leaf spots. In: Kokalis-Burele N, Porter DM, RodríguezKábana R, Smith DH, Subrahmanyam P. (eds) Compendium of Peanut Diseases. 2nd edn. The American Phytopathological Society, St Paul, MN, USA, APS Press, pp 17-20

Song H, Guo Z, Hu X, Qian L, Miao F, Zhang X, Chen J (2019) Evolutionary balance between LRR domain loss and young NBS-LRR genes production governs disease resistance in Arachis hypogaea cv Tifrunner. BMC Genom 20:844

Subrahmanyam P, McDonald D, Waliyar F, Reddy LJ, Nigam SN, Gibbons RW, Rao VR, Singh AK, Pande S, Reddy PM, Subba Rao PV (1995) Screening methods and sources of resistance to rust and late leaf spot of groundnut. In: Information Bulletin No 47. International Crops Research Institute for the Semi-Arid Tropics. Patancheru, Andhra Pradesh 502324, India

Subrahmanyam P, Moss JP, McDonald D, Subba Rao PV, Rao VR (1985) Resistnace to leaf spot caused by Cercosporidium personatum in wild Arachis species. Plant Dis 69:951-954. 
Sujay V, Gowda MV, Pandey MK, Bhat RS, Khedikar YP, Nadaf HL et al. (2012). Quantitative trait locus analysis and construction of consensus genetic map for foliar disease resistance based on two recombinant inbred line populations in cultivated groundnut (Arachis hypogaea L.). Mol Breed 30: 773788. doi: 10.1007/s11032-011-9661-z

Tiwari SP, Ghewande MP, and Mishra DP (1984) Inheritance of resistance to rust and late leafspot in groundnut (Arachis hypogaea L.). Journal of Cytology and Genetics 19:97-101

Udall JA, Quijada PA, Osborn TC (2005) Detection of chromosomal rearrangements derived from homologous recombination in four mapping populations of Brassica napus L. Genetics 169(2):967-979

Varman PV (1999) A foliar disease resistant line developed through interspecific hybridization in groundnut (Arachis hypogaea L.). Indian J Agric Sci 69:67-68

Voorrips RE (2002) Mapchart: software for the graphical presentation of linkage map and QTL.J Heredity $93: 77-78$

Waliyar F (1991) Evaluation of yield losses due to groundnut leaf diseases in West Africa. pp. 32-33. Summary Proceedings of the second ICRISAT regional groundnut meeting for West Africa, 11-14 September 1990. ICRISAT Sahelian Centre, Niamey, Niger. ICRISAT (International Crops Research Institute for the Semi-Srid Tropics) Patanecheru, Andhra Pradesh India

Wang S, Basten CJ, Zeng ZB (2012) Windows QTL Cartographer 2.5. Department of Statistics, North Carolina State University, Raleigh, NC. (http://statgen.ncsu.edu/qtlcart/WQTLCart.htm)

Wang J, Li H, Zhang L, Meng L (2016) Users' Manual of QTL IciMapping. The Quantitative Genetics Group, Institute of Crop Science, Chinese Academy of Agricultural Sciences (CAAS), Beijing 100081, China, and Genetic Resources Program, International Maize and Wheat Improvement Centre (CIMMYT), Apdo. Postal 6-641, 06600 Mexico, D.F., Mexico.

Wynne JC, Beute MK, Nigam SN (1991) Breeding for disease resistance in peanut (Arachis hypogaea L.). Ann Rev Phytopathol29:279-303

Yadav S, Sandhu N, Majumder RR et al. (2019) Epistatic interactions of major effect drought QTLs with genetic background loci determine grain yield of rice under drought stress. Sci Rep 9:2616

Zeng ZB (1994) Precision mapping of quantitative trait loci. Genetics 136: 1457-1468

Zhang H, Chu Y, Dang P, Tang Y, Jiang T, Clevenger JP, OziasAkins P, Holbrook C, Wang ML, Campbell H, Hagan A, Chen C (2020) Identifcation of QTLs for resistance to leaf spots in cultivated peanut (Arachis hypogaea L.) through GWAS analysis. Theor Appl Genet 133:2051-2061. https://doi.org/10.1007/s0012 2-020-03576-2 


\section{Tables}

Table 1: Segregation of LLS resistance in $F_{2}$ and RIL population of the cross VG $9514 \times$ x TAG 24.

\begin{tabular}{|lclll|}
\hline Environment & Resistant & Susceptible & $\chi^{2}$ Value & P value \\
\hline F2 data: Segregation for 1:15 & & & \\
\hline \multicolumn{7}{|l}{ Trombay 2004 } & 14 & 150 & 1.46 & 0.2270 \\
\hline \multicolumn{2}{l}{ RIL data: Segregation for 1:3 } & & & \\
\hline Trombay Kharif 2007 & 51 & 111 & 3.61 & 0.0574 \\
\hline Trombay Kharif 2008 & 50 & 110 & 3.57 & 0.0588 \\
\hline Dharwad Kharif 2008 & 49 & 115 & 2.37 & 0.1237 \\
\hline
\end{tabular}

Table 2: Descriptive statistics of phenotyping data of RILs in different environments

\begin{tabular}{|c|c|c|c|c|}
\hline & \multicolumn{3}{|c|}{ LLS Score } & \multirow{2}{*}{$\begin{array}{l}\text { Percent defoliation at Dharwad } \\
2008\end{array}$} \\
\hline & $\begin{array}{l}\text { Trombay } \\
2007\end{array}$ & $\begin{array}{l}\text { Trombay } \\
2008\end{array}$ & $\begin{array}{l}\text { Dharwad } \\
2008\end{array}$ & \\
\hline Total RILs & 164 & 164 & 164 & 164 \\
\hline Min. Value & 1 & 1 & 1 & 8.33 \\
\hline Max. Value & 9 & 9 & 9 & 90 \\
\hline Mean & 6.26 & 6.14 & 5.42 & 51.82 \\
\hline Std. Error & 0.22 & 0.22 & 0.16 & 1.44 \\
\hline Variance & 8.16 & 7.69 & 4.31 & 341.30 \\
\hline Std. Deviation & 2.86 & 2.77 & 2.08 & 18.47 \\
\hline Median & 8 & 8 & 6 & 54.55 \\
\hline Skewness & -0.53 & -0.60 & -0.43 & -0.31 \\
\hline Kurtosis & -1.45 & -1.36 & -1.09 & -0.32 \\
\hline $\begin{array}{l}\text { Coeff. } \\
\text { Variation }\end{array}$ & 45.61 & 45.17 & 38.28 & 35.65 \\
\hline
\end{tabular}

Table 3: Correlations among LLS field scores and percent defoliation data at Trombay and Dharwad 


\begin{tabular}{|lllll|}
\hline Environment & $\begin{array}{l}\text { LLS Score at } \\
\text { Trombay 2007 }\end{array}$ & $\begin{array}{l}\text { LLS Score at } \\
\text { Trombay 2008 }\end{array}$ & $\begin{array}{l}\text { LLS Score at } \\
\text { Dharwad 2008 }\end{array}$ & $\begin{array}{l}\text { Percent defoliation } \\
\text { at Dharwad 2008 }\end{array}$ \\
$\begin{array}{l}\text { LLS Score at } \\
\text { Trombay 2007 }\end{array}$ & 1.00 & & & \\
\hline $\begin{array}{l}\text { LLS Score at } \\
\text { Trombay 2008 }\end{array}$ & $0.94^{\star *}$ & 1.00 & 1.00 & \\
\hline $\begin{array}{l}\text { LLS Score at } \\
\text { Dharwad 2008 }\end{array}$ & $0.79 \star *$ & $0.81^{\star \star}$ & $0.55^{\star \star}$ & 1.00 \\
$\begin{array}{l}\text { Percent defoliation } \\
\text { at Dharwad 2008 }\end{array}$ & $0.45^{\star \star}$ & $0.40^{\star \star}$ & & \\
\hline
\end{tabular}

Table 4: Details of two main additive QTL and minor QTLs for LLS resistance

\begin{tabular}{|c|c|c|c|c|c|c|c|}
\hline QTL name & Environment & $\begin{array}{l}\text { Peak } \\
\text { position }\end{array}$ & $\begin{array}{l}\text { Left } \\
\text { marker }\end{array}$ & $\begin{array}{l}\text { Right } \\
\text { marker }\end{array}$ & LOD & $\begin{array}{l}\text { PVE } \\
(\%)\end{array}$ & Additive \\
\hline \multirow{4}{*}{$\begin{array}{l}\text { qLLSA02_1 } \\
\text { (main } \\
\text { QTL1) }\end{array}$} & $\begin{array}{l}\text { Trombay } \\
2007\end{array}$ & 33.0 & LS 38b & LS 79 & 27.7 & 41.64 & -2.50 \\
\hline & $\begin{array}{l}\text { Trombay } \\
2008\end{array}$ & 33.0 & LS 38b & LS 79 & 27.8 & 40.85 & -2.60 \\
\hline & $\begin{array}{l}\text { Dharwad } \\
2008\end{array}$ & 33.0 & LS 38b & LS 79 & 7.5 & 45.30 & -1.85 \\
\hline & Average & 33.0 & LS 38b & LS 79 & 17.6 & 38.00 & -2.18 \\
\hline \multirow{4}{*}{$\begin{array}{l}\text { qLLSA02_2 } \\
\text { (main } \\
\text { QTL2) }\end{array}$} & $\begin{array}{l}\text { Trombay } \\
2007\end{array}$ & 89.0 & Ah 282b & RGC 2 & 23.1 & 46.57 & -2.06 \\
\hline & $\begin{array}{l}\text { Trombay } \\
2008\end{array}$ & 89.0 & Ah 282b & RGC 2 & 20.3 & 41.53 & -1.84 \\
\hline & $\begin{array}{l}\text { Dharwad } \\
2008\end{array}$ & 89.0 & Ah 282b & RGC 2 & 11.0 & 27.15 & -1.10 \\
\hline & Average & 89.0 & Ah 282b & RGC 2 & 19.5 & 41.53 & -1.56 \\
\hline qLLSA06 & $\begin{array}{l}\text { Trombay } \\
2008\end{array}$ & 89.0 & TC11A04b & PM 377 & 2.62 & 4.44 & 0.61 \\
\hline qDefolA02 & $\begin{array}{l}\text { Dharwad } \\
2008\end{array}$ & 89.0 & Ah282b & RGC 2 & 3.2 & 41.0 & -10.3 \\
\hline qDefolB08 & $\begin{array}{l}\text { Dharwad } \\
2008\end{array}$ & 219.0 & TE 6 & TE 52 & 2.71 & 8.58 & 7.73 \\
\hline
\end{tabular}

\section{Figures}




\section{$\mathrm{A} 02$}

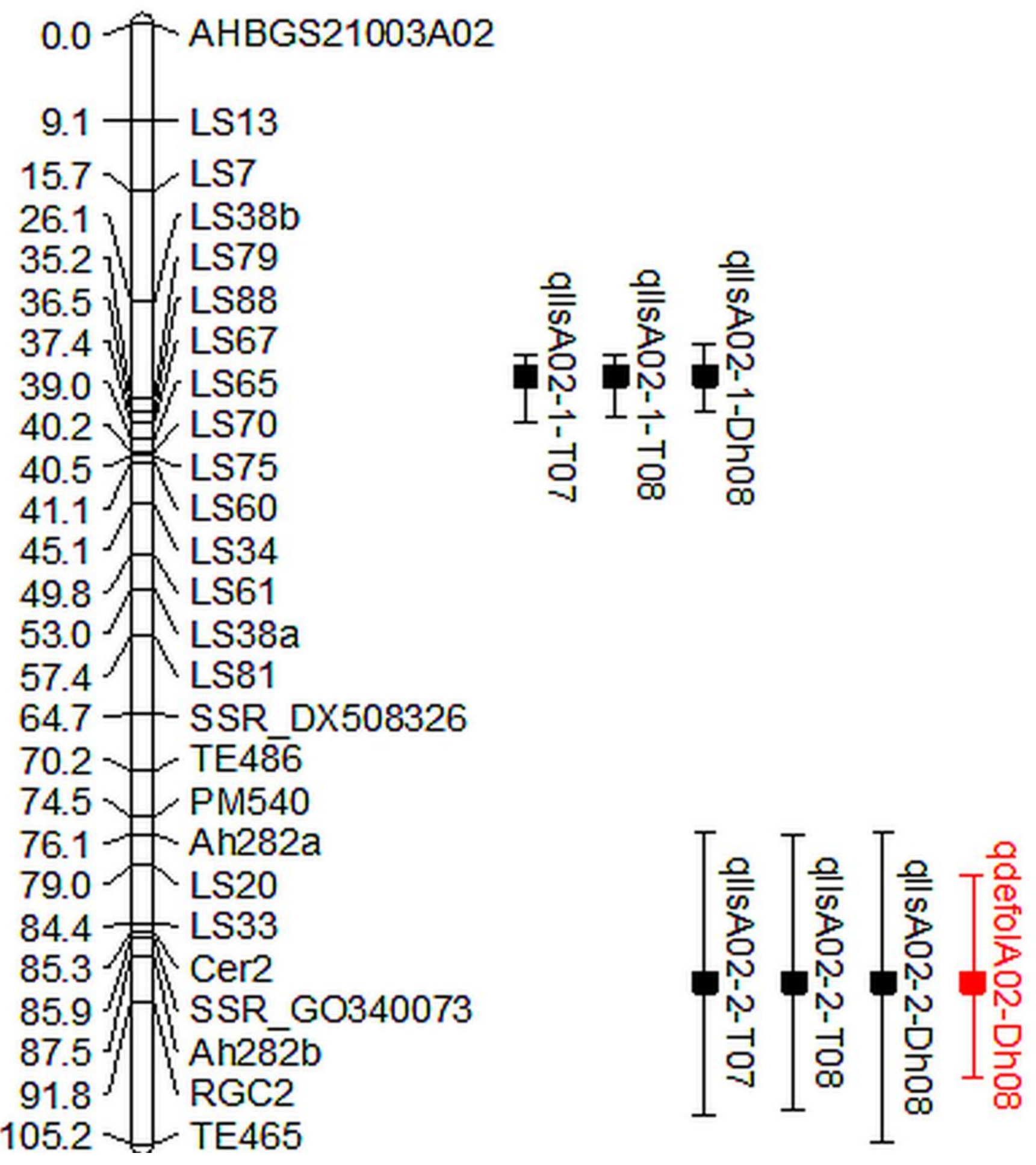

Figure 1

Genetic linkage of LS markers in A02 linkage group and position of two major QTLs for LLS resistance. 

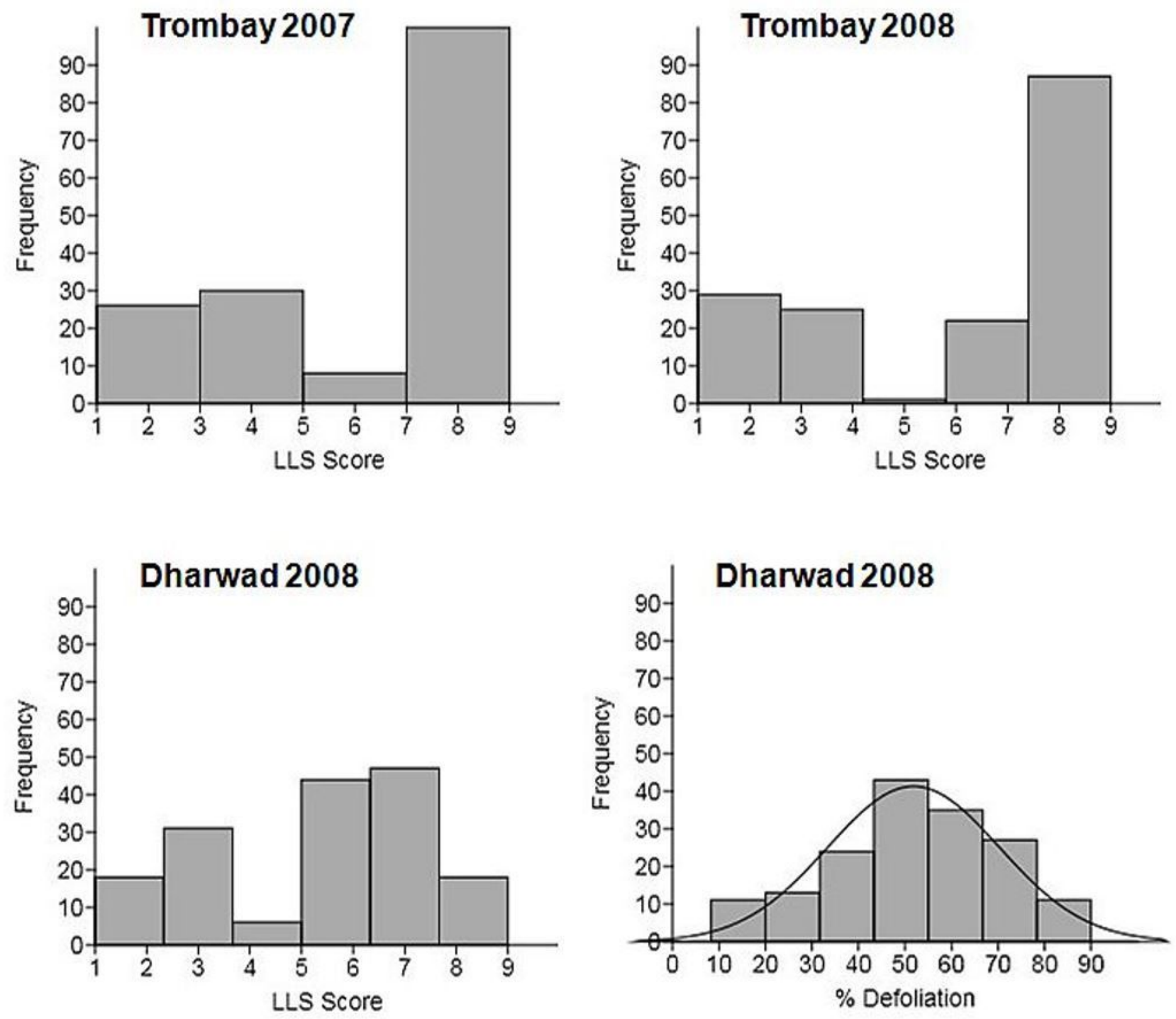

Figure 2

Histogram distribution of field LLS score and percentage defoliation data of RILs in different environments 


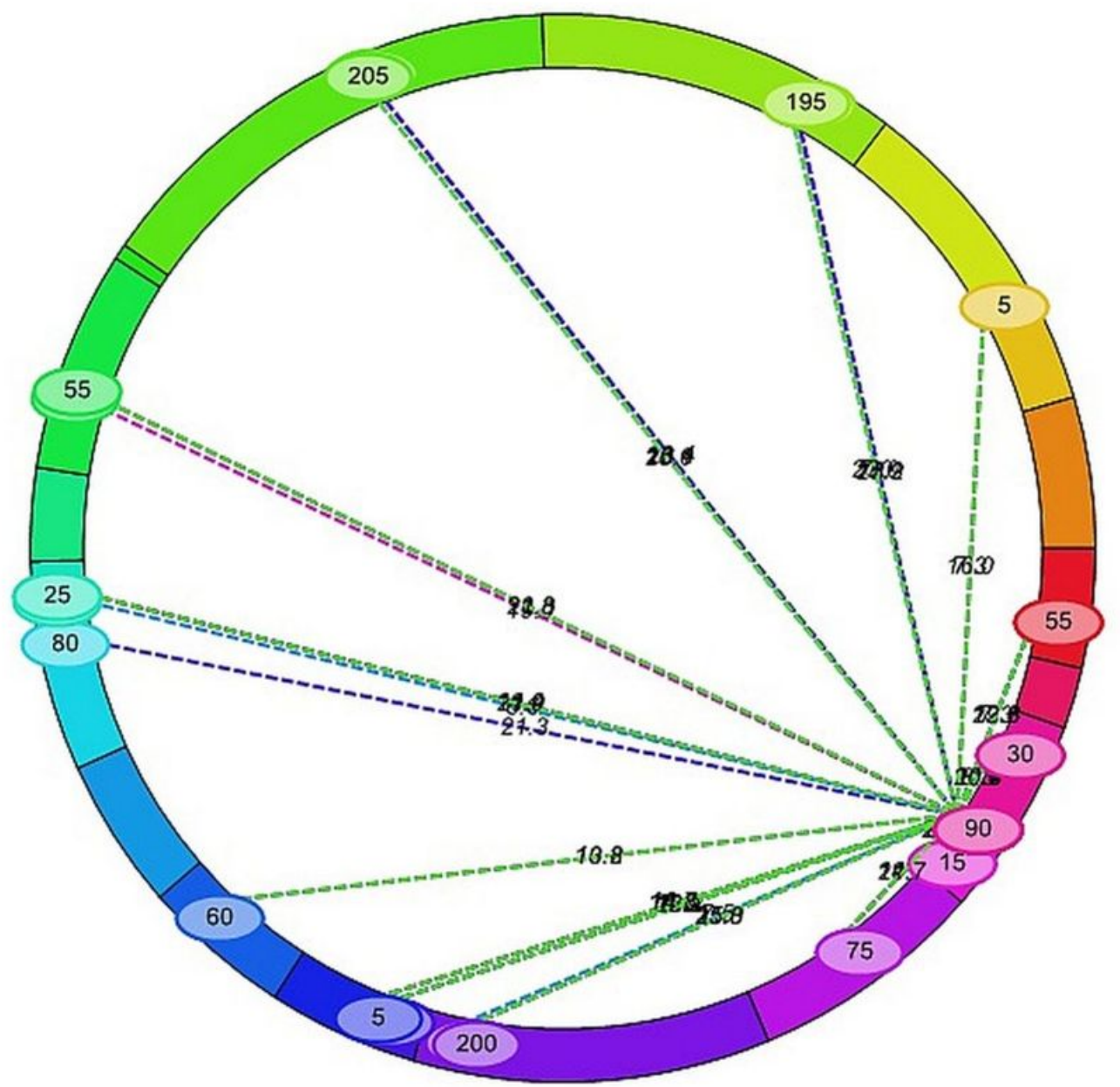

$\begin{array}{ll}\square & \text {-Ch1 } \square \text {-Ch19 } \\ \square & - \text { Ch2 } \square-\text {-Ch20 } \\ \square & - \text { Ch3 } \\ \square & - \text { Ch4 } \\ \square & - \text { Ch5 } \\ \square & - \text { Ch6 } \\ \square & - \text { Ch7 } \\ \square & - \text { Ch8 } \\ \square & - \text { Ch9 } \\ \square & - \text { Ch10 } \\ \square & - \text { Ch11 } \\ \square & - \text { Ch12 } \\ \square & - \text { Ch13 } \\ \square & - \text { Ch14 } \\ \square & - \text { Ch15 } \\ \square & - \text { Ch16 } \\ \square & - \text { Ch17 } \\ \square & - \text { Ch18 }\end{array}$

Figure 3

Schematic diagram of epistatic QTLs over cultivated groundnut genome Note: Ch1 = linkage group A01, $\mathrm{Ch} 2=\mathrm{B} 01, \mathrm{Ch} 3=\mathrm{A} 02, \mathrm{Ch} 4=\mathrm{B} 02, \mathrm{Ch} 5=\mathrm{A03}, \mathrm{Ch} 6=\mathrm{B} 03, \mathrm{Ch} 7=\mathrm{A04}, \mathrm{Ch} 8=\mathrm{B} 04$ and so on 